\title{
Preserving Popular Culture
}

\author{
by R. Neil Fulghum
}

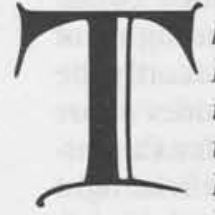

he North Carolina Collection, a special collection in Wilson Library at the University of North Carolina at Chapel Hill, is the largest single research collection in the nation devoted to one state. Tracing its history on campus to 1844 , the North Carolina Collection pursues its mission of acquiring literature either written about North Carolina or material written by North Carolinians. The collection contains over a quarter of a million items. Printed materials, such as books $(116,945)$ and pamphlets $(76,634)$, constitute the great majority of the collection. ${ }^{1}$ However, the collection also includes microforms, sound recordings, films, videos, an extensive photographic archives, and nearly 12,000 historic properties, such as antique furniture, oil portraits, framed prints and drawings, statuary, North Carolina currency, and university "keepsakes." Many of these artifacts are displayed in the new North Carolina Collection Gallery where they complement printed material in short- and

long-term exhibitions.

Scattered throughout the North Carolina Collection's holdings are many items that would beclassified as examples of popular culture. These include paperback romances, science fiction, detectivenovels, and biographies of sports figures such as Michael Jordan, Jim "Catfish" Hunter, and stock car racer Richard Petty. The collection has phonograph albums by pop vocalist James Taylor, comedians Jackie "Moms" Mabley and Andy Griffith, and television personality Charles Kuralt. Memorabilia of Carolina's basketball triumphs, such as commemorative pop drink containers and films, also have a place in the collection.

In 1933 the German writer Hanns Johst wrote in Schlageter, "When I hear the word 'culture' I reach for my revolver." 2 Today many librarians may have the same impulse when faced with the tasks of cataloging, preserving, circulating, or exhibiting the growing body of material classified as popular culture. While academics and cultural philosophers debate the relative importance of popular culture, it is librarians who must deal directly and daily with the real problems of allocating shelf space for their institutions' collections of popular culture material, organizing those acquisitions, and preserving them.

Today librarians may consider any of three courses of action when confronted with popular culture items in their collections: discard them; box and forget them; or care for them and, as much as possible, extend their lives and availability to the public. It can be argued that historically and ethically speaking, all cataloged materials in a library collection should be valued equally when considering their long-term care and handling, since all are potentially important documentation of our past. We should preserve the "vulgar" as well as the sublime, the ephemeral as well as that thought to be enduring, and let future scholars decide what is worthwhile and what items best show the evolution of our society. In reality, though, financial constraints, limited supplies, cramped facilities, intellectual elitism, and accompanying collection biases among staff result in the establishment of priorities when allocating money for preservation. Decisions must be made between archival and non-archival holdings, what to save and what to let perish without intervention. For small local or regional libraries - libraries that consider their holdings to be primarily circulating collections and not archival in status - such realities make ludicrous the purist's demand that all materials be treated equally. These libraries cannot treat a pulp copy of a recently published science fiction novel as they would the library's unique copy of a local history pamphlet or first edition of Thomas Wolfe's Look Homeward, Angel. Time has demonstrated, however, that the common eventually becomes scarce, and that items initially regarded as "vulgar" popular culture can become classics. For example, Johann Goethe's morbidly romantic The Sorrows of Young Werther or Pierre Choderlos de Laclos's titillating Dangerous Liaisons could have been considered vulgar by late eighteenth-century European intellectuals. And in today's American history museums, curators would pay handsomely, or gladly exchange several of their Confederate officers' uniforms, for the much rarer butternut jacket of a lowly Rebel private. What was once mass produced is now frequently the scarcest and most coveted.

Another reality to consider when debating whether to collect and preserve popular culture is that many library patrons do not distinguish between "high" culture and pop culture. The exhibition of popular culture items can be important, for the long-term preservation and proper exhibition of popular culture materials can attract a wide audience, lead to the donation of other collections, and generate support for library projects. Yet, popular culture material obviously mishandled in a library or carelessly shelved or exhibited may cause visitors, researchers, and potential donors to question the general care given to collections by library staff. It should therefore be emphasized to staff that the life of all material, even that doomed to acidic 
disintegration or perceived as ultimately expendable, can and should be extended by following basic preservation procedures and by being mindful of the particular environmental and security conditions in one's own institution.

\section{Environment}

The first and most important preservation concern in shelving or exhibiting any material remains environmental stability, with attention focused on light, temperature, and relative humidity. No professional librarian should be ignorant of acceptable environmental parameters or ignore basic environmental problems. The life of all materials should and can be extended by careful handling and by properly adjusting, even slightly, stack and exhibit area environments.

Light in any form damages library material to some degree. The librarian's goal should be to minimize damage to the extent that the institution's budget, public-access policies, and architectural design will allow. Two types of illumination, natural and artifical light, affect collections in nearly every institution. A spectrum of light, which is measured in nanometers, is generally divided into short and long wavelengths, from ultraviolet to visible to infrared ranges. The ultraviolet (UV) portions-those shorter waves under 400 nanometers - do the greatest damage to paper, inks, leather, textiles, photographic emulsions, and other media. ${ }^{3}$ Daylight has the most UV that may leak, filter, or pour into reading rooms, shelf spaces, and exhibit areas through windows, glass doors, or skylights. A light source's ultraviolet radiation, its intensity of illumination, and its heat concentrations are the chief concerns. These conditions accelerate the oxidation and deterioration of organic material, causing them to fade, harden, crack, or undergo some other deformation in a relatively short time. Cheaper, uncoated papers and inferior inks are particularly vulnerable to ultraviolet radiation. Publications on newsprint, such as comic books, turn yellow and their acidic papers rapidly deteriorate with exposure to ultraviolet. The damage incurred by a home-delivered newspaper sitting in one's driveway under a single day's sun demonstrates the results of such exposure. Even small doses of ultraviolet over an extended amount of time will have the same telling effects.

Sunlight entering a building can be either filtered or entirely blocked out by painting or covering the interiors of windows with opaque panels or adhesive films. Lightweight, rigid foam material sandwiched between moisture-resistant surfaces (for example, Gatorfoam $(\AA$ made by International Paper Company) is doubly effective-it blocks light and it insulates. Painting or using opaque panels is preferable to installing drapes or blinds, since drapes and blinds are very efficient dust collectors.

Often, however, it is not possible to cover a window completely because patrons and staff need visual access to a building's exterior. Special transparent, adhesive films with UV-filtering capability can be applied to window glass, although bubbling in such films sometimes occurs during application and cracking or "crazing" in the film may be evident after several years of exposure to daylight and seasonal temperature extremes. More expensive, clear plastic filtering panels, such as Plexiglas ${ }^{\circledR}$ or Oroglas UF-3® (available through Rohm \& Haas Company and other companies) are the preferred and more durable method of filtering the harmful natural UV light. These heavier plastic panels can be cut to fit any window and attached to window interiors with hooks-and-loops or Velcro ${ }^{\circ}$ strips on the panel's edge or frame. Such UF-3 panels have been installed over the four large twenty-four-pane windows in the North Carolina Collection Gallery's main exhibit area. These panels effectively filter out over ninety percent of daylight UV, and because they were installed with Velcro, it is fairly simple to replace or clean them. The panels also act as storm windows, creating a buffering air space between the original window and the panel insert. 4

The illumination of collections areas and exhibit cases with artificial lights also creates preservation problems. Both UV radiation and radiant heat can damage stored or exhibited materials. The intensity of both incandescent and fluorescent lamps should always be adjusted, with their wattages minimized as much as possible. It is a mistake, especially when lighting case interiors, to consider fluorescent lamps safe from heat buildup. While fluorescents are often considered a cooler light source than incandescent fixtures which produce light from a coiled tungsten filament, most fluorescent and incandescent lights of equal wattage emit a nearly equal amount of heat. It is only the elongated shape of fluorescent tubes, which provides more surface area for the diffusion of heat, that accounts for fluorescent bulbs feeling cooler to the touch. Of the two artificial light sources, fluorescent has the added risk of having a much higher proportion of UV. Since incandescent lamps emit comparatively low amounts of $U V$, it usually is not necessary to filter these light sources. Installing flexible UV-filtering shields, costing approximately $\$ 3.50$ each, over all fluorescent fixtures in stack or exhibit areas is advisable. If financial constraints prevent a library from shielding all the lamps at one time, staff should establish priorities for shielding and install a series of filters each year, or in stages. For fluorescent lights inside exhibit cases, only rigid plastic UV-filtering covers, cylindrically shaped with end caps to fit over the fluorescent tube, should be used. These covers filter harmful radiation and,

in the event that a fluorescent tube ruptures or shatters, the covers provide added protection for exhibited material by preventing the sudden release of the bulb's phosphor gas and the dispersal of fine bits of glass within the enclosed space.

It is much easier to control lighting than it is to stabilize the temperature and humidity within a library. Many older structures require expensive modifications or entirely new heating and air conditioning systems. Without the aid of expensive thermohydrographs to measure temperature and relative humidity (RH), it is difficult for the librarian to detect from one day to the next slight changes in a room's environmental conditions. Slight but increasing levels of humidity finally reveal themselves in the mold or foxing that begins to blotch paper and grow on phonodiscs and on magnetic tape. Every library, even those that cannot afford sophisticated equipment, should regularly take basic readings of the environment and be aware of the range of its fluctuations and seasonal extremes. Cheaper, less accurate monitors are preferable to no equipment at all. Inexpensive thermometers and RH indicator cards, which change color in response to variations in relative humidity, should be placed in several locations throughout a facility. Humidity indicator cards can be used for years, are available through many suppliers (including Light Impressions and University Products), and cost less than $\$ 1.25$ each. 5

To minimize damage to general collections, a library's atmospheric temperature should be set at 68 to 70 degrees Fahrenheit, with a stable relative humidity of 55 percent (+or $-5 \%)$. Although sound archivists recommend slightly drier environments for magnetic tape, consistent $\mathrm{RH}$ readings of less than forty percent, 
especially when combined with higher range temperatures, will embrittle paper, crack leather bindings, and significantly weaken textile fibers. 6 Consistently low humidity can create static electricity that causes paper and textiles to stick together and abrade. It also causes dust to adherestubbornly to phonodiscs and other collections. Relative humidity levels above sixty-five percent invite mold growth and mildew. 7 To eliminate humidity concentrations in storage and display cases, portable dehumidifying equipment or reusable water-absorbing agents can be used. A small, perforated container filled with granulated silica gel, a desiccant, cannot significantly affect an entire room's humidity, but it can reduce humidity and provide safer environments for material in confined spaces, such as boxes, drawers, and cabinets. Silica gel costs very little and can be reused indefinitely if baked periodically in an oven at three hundred degrees to remove the moisture it has absorbed.

Often, simple precautions can prevent moisture damage and foxing. For instance, whenever possible, framed materials (particularly those with overlying glass or acrylic glazing) should not be mounted on a library's interior perimeter walls. These walls absorb and transfer outside seasonal temperatures to the back of framed maps or illustrations. This increases the chance of condensation and moisture build-up within the frame as the heat or cold from the building's exterior interacts with the air conditioned or heated environment of the interior. The moist atmosphere created between the glass and the matted document or picture is a fertile area in which ever-present spores reactivate and mold develops and takes hold. Also, when framing and matting items such as an original pop music score written in pencil, or that prized charcoal portrait of Elvis, one should use only glass. Never install objects produced in these media behind plastic glazing. With environmental changes, acrylic and other plastic coverings often become charged with static electricity, which means that significant amounts of graphite, chalk, charcoal, or other granular media literally can be pulled off the pages and onto the plastic.

\section{Audiovisuals}

A growing amount of popular culture material is in audiovisual formats. Permanence is not a characteristic of circulating audiovisual materials or even of archivally stored sound and image recordings. Over time, phonodiscs are scratched, motion-picture film decomposes, and magnetic tape breaks or sheds its oxide coatings. The immediate and most important preservation considerations for music collections are proper storage and climatic control. Gaining a quick, basic knowledge of the respective shelf lives and storage requirements of different sound and image formats can be done by contacting established popular music collections, such as those at Georgia State University and at Middle Tennessee State University. Audiovisual formats have, archivally speaking, a very short life span, and it should be emphasized that the necessary transfer of sound and image recordings to other new formats is a very expensive procedure. Sound archivists consider commercially produced, vinyl phonograph albums far more chemically stable and longer lasting than today's magnetic tape or compact discs. Consequently, the older vinyl recordings of rock-and-roll musician Buddy Holly will probably outlive Madonna's latest compact disc. Magnetic tapes have a projected average life expectancy of only twenty years, as do commercial compact discs due to their very unstable polycarbonate bases. Some tapes, of course, may last forty years, others only five. Film and videotape have the same variances in the quality of material used in their manufacture and in their respective preservation needs. New technologies in archival digital formats may one day extend the life of sound and image recordings to one hundred years. Therefore, all the recorded sounds and all the recorded images of our past await and require transfer to other, more stable audiovisual formats; otherwise, most will likely be lost within one or two generations of time. The instability of this nonprint material demands even greater cooperation and networking between libraries and with museums and other cultural institutions. Expertise must be widely distributed and unnecessary duplication of records avoided in preserving this growing body of material. ${ }^{8}$

\section{Conclusion}

Conditions and decisions regarding the acquisition and preservation of popular culture material vary. Regardless of the ultimate decisions and despite budget restraints, all librarians should know the environmental conditions of their institution. No library will ever establish the perfect storage or exhibit environment, nor meet all the preservation needs of its collection and save all of its holdings. Nor will the perfect balance between preservation and public access to a library's holdings ever be found. For their popular culture material, for the good of their entire collection, librarians must put away their revolvers, persevere, and prolong as best they can the life of the records under their temporary care.

\section{References}

${ }^{1}$ H. G. Jones, Annual Reports of the North Caroliniana Society, Inc., and the North Carolina Collection (Chapel Hill: North Caroliniana Society, Inc., 1992), 52.

2 George Seldes, compiler, The Great Thoughts (New York: Ballantine Books, 1985), 214.

3 Garry Thomson, The Museum Environment (London

Butterworths and Company, 1986), 16-19.

${ }^{4}$ S. Thomas Shumate, Jr., "Specifications: Storm Windows for Wilson Library," unpublished bid proposal, 1986, section 0865 , p. 3. Facilities Planning Office, University of North Carolina at Chapel Hill.

5 Light Impressions Corporation, Light Impressions [supply catalog] (Rochester: Light Impressions Corporation, summer 1992), 44

6 Alan Ward, A Manual of Sound Archive Administration (Aldershot, England: Gower Publishing Company, 1990), 100101.

7 Per E. Guldbeck, The Care of Antiques and Historical Collections $2 \mathrm{~d}$ ed., rev. and expanded. (Nashville: American Association for State and Local History, 1985), 22.

8 Interview with Michael Casey, Sound and Image Librarian, Special Collections, University of North Carolina at Chapel Hill, July 7, 1992. 